\title{
Erratum to: Quantum Chemical Calculations on Two Compounds of Proquazone and Proquazone Type Calcites as a Calcium Sensing Receptor (CaSR) Inhibitory Profiles
}

\author{
Ahmed Hassen Shntaif ${ }^{a, *}$, Zahraa M. Rashi ${ }^{b, d}$, Zaid H. Al-Sawaff ${ }^{c, d}$, and Fatma Kandemirli ${ }^{e}$ \\ ${ }^{a}$ Chemical Department, Collge of Science for Woman, Babylon University, Babylon, Iraq \\ ${ }^{b}$ Electronic Technical Department, Babylon Institute, Al-furat Al-awsat Technical University, Najaf, Iraq \\ ${ }^{c}$ Materials Science and Engineering, Faculty of Engineering and Architecture, Kastamonu University, Kastamonu, 3700 Turkey \\ ${ }^{d}$ Medical Instrumentation Technology, Technical Engineering College, Northern Technical University, Mosul, Iraq \\ ${ }^{e}$ Biomedical Engineering Department, Faculty of Engineering and Architecture, \\ Kastamonu University, Kastamonu, 3700 Turkey \\ *e-mail:ahmed_79sh@yahoo.com \\ Submitted July 9, 2021; accepted for publication July 9, 2021
}

DOI: $10.1134 / \mathrm{S} 106816202134001 \mathrm{X}$

The name of the second author should read Zahraa M Rashid.

The original article can be found online at https://doi.org/10.1134/S106816202103016X 